\title{
Coronaviruses fusion with the membrane and entry to the host cell
}

\author{
Ewelina Wędrowska ${ }^{1, A, C-D \oplus}$, Tomasz Wandtke ${ }^{1, A, C-D \oplus}$, Tomasz Senderek ${ }^{2, C \oplus}$, Elżbieta Piskorska ${ }^{3, E \oplus}$, \\ Piotr Kopiński ${ }^{4, F} \odot$ \\ 1 Department of Lung Diseases, Neoplasms and Tuberculosis, Collegium Medicum, Nicolaus Copernicus University, Toruń, \\ Poland \\ ${ }^{2}$ Department of Physiology and Pathophysiology, Andrzej Frycz Modrzewski University, Kraków, Poland \\ ${ }^{3}$ Department of Pathobiochemistry and Clinical Chemistry, Nicolaus Copernicus University Collegium Medicum, \\ Bydgoszcz, Poland \\ ${ }^{4}$ Center for Medical Research and Technology, John Paul II Hospital, Kraków, Poland \\ A - Research concept and design, B - Collection and/or assembly of data, C - Data analysis and interpretation, \\ $D$ - Writing the article, E-Critical revision of the article, $F$ - Final approval of article
}

Wędrowska E, Wandtke T, Senderek T, Piskorska E, Kopiński P. Coronaviruses fusion with the membrane and entry to the host cell. Ann Agric Environ Med. 2020; 27(2): 175-183. doi: 10.26444/aaem/122079

\begin{abstract}
Introduction. Coronaviruses (CoVs) are positive-strand RNA viruses with the largest genome among all RNA viruses. They are able to infect many host, such as mammals or birds. Whereas CoVs were identified 1930s, they became known again in 2003 as the agents of the Severe Acute Respiratory Syndrome (SARS). The spike protein is thought to be essential in the process of CoVs entry, because it is associated with the binding to the receptor on the host cell. It is also involved in cell tropism and pathogenesis. Receptor recognition is the crucial step in the infection. CoVs are able to bind a variety of receptors, although the selection of receptor remains unclear. Coronaviruses were initially believed to enter cells by fusion with the plasma membrane. Further studies demonstrated that many of them involve endocytosis through clathrin-dependent, caveolae-dependent, clathrin-independent, as well as caveolae-independent mechanisms.

Objectives. The aim of this review is to summarise current knowledge about coronaviruses, focussing especially on CoVs entry into the host cell. Advances in understanding coronaviruses replication strategy and the functioning of the replicative structures are also highlighted. The development of host-directed antiviral therapy seems to be a promising way to treat infections with SARS-CoV or other pathogenic coronaviruses. There is still much to be discovered in the inventory of proand anti-viral host factors relevant for CoVs replication. The latest pandemic danger, originating from China, has given our previously prepared work even more of topicality.
\end{abstract}

\section{- Key words}

coronavirus, spike protein, membrane fusion, viral entry, nonstructural proteins, replication complex

\section{INTRODUCTION}

Coronaviruses (CoVs) are positive-strand RNA viruses from the Coronavirinae subfamily which, together with Torovirinae, belong to the large Coronaviridae family in the Nidovirales order. The Coronavirinae subfamily is divided into different genera of alphacoronavirus ( $\alpha$-genus), betacoronavirus ( $\beta$-genus), gammacoronavirus ( $\gamma$-genus) and deltacoronavirus ( $\delta$-genus) [1].

Coronaviruses are able to infect a variety of mammals and other species. CoVs infections cause especially enteric and respiratory diseases in humans, including the common cold, as well as diseases in animals, Infrequently they are the reason for hepatitis and multiple organ failure [2]. The first member of the coronaviruses was identified in the 1930s [3], and in the 2003 they have become known again and classified as agents of Severe Acute Respiratory Syndrome (SARS) [4]. SARS-CoV is a human enveloped coronavirus with single positive-strand RNA of $25-31 \mathrm{~kb}$ with a 5 'cap and 3'-poly(A) tail [5]. In 2002-2003, SARS-CoV caused almost 8,000 infections with a mortality rate of $10 \%[6,7]$.

Address for correspondence: Ewelina Wędrowska, Department of Lung Diseases, Neoplasms and Tuberculosis, Collegium Medicum, Nicolaus Copernicus University, Toruń, Poland

E-mail: ewelina.wedrowska@gmail.com

Received: 23.02.2020; accepted: 06.05.2020; first published: 15.05.2020
Middle East Respiratory Syndrome Coronavirus (MERSCoV), first identified in Saudi Arabia in 2012, is also highly pathenogenic. As of 4 December 2015, 1,621 laboratoryconfirmed cases of infection with MERS-CoV were notified with approximately $36 \%$ mortality (584 deaths related to MERS-CoV) [8]. Currently, the rapidly-spreading COVID-19 pandemic, caused by SARS-CoV2 is being observed. The number of patients increases rapidly and as of 2 April 2020, there are over a million confirmed cases, and more than 50 thousand deaths [9].

\section{OBJECTIVES}

The aim of th study is to summarise current knowledge about coronaviruses and review the results of studies on CoVs entry into the host cell. Advances in understanding coronaviruses replication strategy and the functioning of the replicative structures are also highlighted.

Coronavirus genome. The size of the Coronaviruses varies from 80-120nm. Their 5'-capped single-positive strand RNA genome encodes 4-5 structural, 15-16 nonstructural and 1-8 accessory proteins [10]. The 5'- and 3'-ends of the CoVs genome consists of Untranslated Regions (UTRs) with cis-acting elements essential for viral replication and transcription. 
CoVs genome size ranges from $26.2-31.7 \mathrm{~kb}$ and contains $6-10$ Open Reading Frames (ORFs) [11]. The first ORF (ORFla and ORF1b) encodes the replicase proteins and extends over $2 / 3$ of the $\mathrm{CoV}$ genome. The replicase is a mandatory factor for the transcription of both: genomic (full-length) minus-strand template and subgenomic (discontinuous transcription) minus strand synthesis. As a result of polyproteins processing by proteinases, 16 non-structural proteins are generated. No-structural protein 3 (nsp3), non-structural protein 4 (nsp4) and non-structural protein 6 (nsp6) are considered to be responsible for the stability of the CoVs Replication/ Transcription Complex (RTC). The remaining 1/3 of the ORF1 encodes 4 structural proteins: $\mathrm{S}$ (spike protein), E (envelope protein), $\mathrm{M}$ (membrane protein) and $\mathrm{N}$ (nucleocapsid protein). The $\mathrm{M}$ and $\mathrm{E}$ proteins are responsible for the assembly of the virions, whereas the $S$ protein allows viral entry into the host cell, while the $\mathrm{N}$ protein is required for encapsidation of viral RNA. However, some of the CoVs also contain the additional HE (hemagglutinin esterase) viral protein, which is known to be involved in the host cell membrane interactions $[10,11$, 12]. These structural proteins are created by discontinuous transcription during the subgenome minus-strand RNA synthesis $[13,14]$. The genomic positive-sense RNA is rewritten into a negative-sense RNA template by RNA-dependent RNA polymerase (RdRp). Then, RdRp has the possibility to move to the 5'-end to finish the negative subgenomic (sg) mRNA, which might be a template for the positive-sense sgRNA synthesis. It has been shown that only the first unique gene from 5 '-end of all sgRNA is translated. It last approximately 75-90 minutes, untill both minus and plus-strand RNA can $\mathrm{d}$ be detected after the infection $[15,16,17,18]$.

Spike protein as the main agent of coronavirus cell entry. The spike protein plays a major role in the entry to the host cell. The infection is caused by a viral particle which interacts with the host receptors on the cell surface. This viral and cellular fusion triggers conformation of the $S$ protein [19] which regulates cell tropi and host range, and also is involved as a main target of neutralizing antibodies during infection [20].

The coronavirus spike is athe class I of transmembrane proteins, with a typical size ranging from 1,160-1,400 amino aci, and contains 21-35 N-glycosylation sites. Many studies have demonstrated that fusogenic conformational changes cause the generation of trimers composed of harpins on the virion surface $[21,22,23,24]$.

As a member of the class I viral fusion proteins [25, $26,27,28]$, the spike protein is consists of 3 segments: an ectodomain, a single-pass transmembrane anchor, and a short intracellular tail $[29,30]$. The ectodomain of the $S$ protein consists of 2 domains: S1 (N-terminal), which is responsible for binding to the receptor and subsequently attaching the virion to the cell membrane, and the S2 (C-terminal), the most conserved region of the spike protein. The S2 subunit includes domains involved in membrane fusion: fusion peptide (FP), heptad repeat domains-1 and -2 (HR1, HR2) and the transmembrane domain (TM) [31]. Commonly, domains of the spike protein remain connected in alpha- and majority of beta-corona viruses, but in gamma- and also same cases of beta-coronaviruses the spike protein is divided between those domains [19]. The S1 domain has 2 independent subdomains: N-terminal (S1-NTD) and C-terminal (S1-CTD). Both exhibit ability to bind molecules, sugars or proteins, as receptor binding domains (RBDs) [19]. RBDs enclose primary neutralization epitopes, activate host response, and for this reason might be a part of vaccines directed against infections caused by coronaviruses [20, 32, 33, 34, 35, 36].

Trimers of harpins consist 2 heptad-repeat regions (HR) in the S2 domain. They are assembled as prolonged triple helical coiled-coil motif(HR1) surrounded by 3 HR 2 motifs, which are much more shorter [37, 38, 39]. Some studies have already been conducted on the crystal structure of CoVs RBDs, together with their cognate receptors [40, 41]. Casais at al. also demonstrated the $S$ protein importance in tropism. They decided to use a recombinant Infectious Bronchitis Virus (IBV), a member of the Coronaviridae that replicates primarily in the respiratory tract as well as in epithelial kidney cells [42]. IBV strains are able to infect only chicken embryo cells. Thus, the authors decided to produce the rIBV in which the Beaudette $S$ glycoprotein gene in Beau-R was replaced with the corresponding sequence derived from IBV M41-CK $[43,44]$. The IBV Beaudette strain is able to spread in CK, CEF, BHK-21, and also in Vero cells. As opposed to IBV Beaudette, IBV M41-CK can only infects CK cells [45]. These differences provide examination of the cell tropism mechanism. They investigated BeauR-M41(S), a recombinant infectious bronchitis virus (rIBV), in which the ectodomain region of the $S$ gene from IBV M41-CK was replaced by the corresponding region of the IBV Beaudette genome. As a result, BeauR-M41(S) obtained the same cell tropism as IBV M41-CK in different cell types, and indicated that spike protein is a determinant of cell tropism [42].

The chimeric virus is another example that perfectly shows the importance of the $S$ protein regarding cell tropism. Mouse hepatitis virus (MHV) strains cause hepatic, neurological, respiratory and enteric diseases. One of the most studied is the weakly neurovirulent A59 strain, which causes moderate hepatitis and acute encephalitis. It undergoes clearance from the central nervous system (CNS) and the liver by strong CD8 T-cell response. Unfortunately, the viral RNA usually remains in the spinal cord and causes acute infection [46, 47, 48]. The JHM strain (also called JHM. SD or MHV-4), is highly neurovirulent and causes fatal encephalitis and only minimal hepatitis, while the MHV-2 strain is highly hepatotropic. By introduction of the JHM genes to the MHV-A59 strain, Navas at al. have shown enhanced virulence of the recombinant virus, which occurs by MHV receptor CEACAMla-dependent and independent mechanisms as well as hepatotropism, and thereby the major role of the $S$ protein in determination of organ tropism and neurovirulence $[49,50]$. Replacement of the spike protein in A59 by the S protein from JHM causes a robust neurovirulent phenotype of the recombinant A59 virus (rA59). This chimera caused increased inflammation and the rate of viral antigen spread, compare $3 d$ to the wild type of A59 [51, 52, 53].

Finally, Walls et al. contributed to the understanding of CoVs entry. They produced a mutated MHV S ectodomain trimer with enhanced stability, and therefore high affinity to the CEACAM1 receptor, and determined its structure at 4.0 Å resolution by single particle cryo-electron microscopy. They proved that the $\mathrm{S}$ trimer has 3 central helices that are packed through a central part. The S1 subunit has a ' $\mathrm{V}$ ' shape. The $\mathrm{N}$-terminal subdomain is mostly composed of domain $\mathrm{A}$, while $\mathrm{C}$-terminal are $\beta$-rich domains. S2 domains contain long $\alpha$-helices and are associated with membrane. Researches highlight that this domain is especially similar to 
the paramyxovirus F proteins with the core, central helix and upstream helix. They also indicated that in the conformation of pre-fusion, the S1 subunits interlock and therefore form a crown around the S2 trimer stabilizing it [54].

There is a verylarge similarity between the S1NTD structures and human galectin. S1NTD adopts $\beta$-sandwich fold where 2 anti-parallel $\beta$-sheet layers form a core structure. Depending on the genera, an $\alpha$-helix ( $\alpha$ and $\delta$ coronaroviruses) or a celling-like structure ( $\beta$-coronaroviruses) is attached to the upper part of the core. Three-stranded $\beta$-sheet and another $\alpha$-helix are attached to the bottom of the core structure, regardless of the type of virus. Research on the structure and functions S1-NTDs from different genera coronaroviruses suggest that all of them have the same evolutionary origin, and acquired the galectin gene from the host and included it in their spike gene which began to encode S1-NTD. Next the galectin fold was preserved during evolution $[55,56]$.

Coronaroviruses $\alpha, \beta$ and $\delta$ show the same structural topology but different structural folds in terms of their S1-CTDs. coronarovirus a S1-CTD has a $\beta$-sandwich core structure and is similar to the $\delta$ coronaroviruses S1-CTDs which containing $2 \beta$-sheet layers: one is a 3 -stranded antiparallel $\beta$-sheet, the second is a 3 -stranded mixed $\beta$-sheet. $\beta$-coronavirus S1-CTDs has a $\beta$-sheet core. Coronarovirus $\alpha$ and $\delta$ S1-CTDs core contains receptor binding motifs (RBMs) on the top in the form of 3 loops, but the closed conformation of the S1-CTD prevents binding of the receptor. To bind its receptor, the S1-CTD would need change conformation to an open structure. The RBM in $\beta$-coronavirus S1-CTD is a long continuous subdomain.

The structures of SD1 and SD2 are similar to those of their counterparts in $\alpha$ - and $\beta$-coronavirus spikes. Both of them adopt a small $\beta$-sandwich fold, except that SD1 contains 2 antiparallel $\beta$-sheets (2-stranded and 5-stranded), and SD2 contains 2 three-stranded $\beta$-sheets. Two S1 subdomains connect S1 and S2. There are both structural and mechanistic similarities between coronarovirus S2 and influenza HA2. This suggests that the 2 viral membrane fusion proteins are evolutionarily related. Parts of S2 form 6-helix bundle structures corresponding to HR-N and HR-C. The similarity betweethe influenza virus and coronaroviruses allows some assumptions to be made about the construction and principles of S2. Regardless of this assumption, should be confirmed by the atomic structure of po-fusion CoVS2 $[55,56]$.

The $\mathrm{N}$ protein as a virulent principle. The nucleocapsid protein ( $\mathrm{N}$ protein) is an RNA binding protein that interacts with the $M$ protein during e virion assembly. It is also involved in the formation of the viral capsid [57] and plays an important role in the replication. First of all, it associates with both the genomic and subgenomic mRNA [58], as well as with the microtubules [59]. Moreover, $\mathrm{N}$ protein blocs the activity of L RNase by being the antagonist of type I Interferon (IFN) [60], and also inducts the fibrinogen-like protein 2 , subsequently causing the increase of liver damage after infection $[61,62,63]$.

The nucleocapsid protein consists of 2 domains, an $\mathrm{N}$-terminal (N-NTD) and a C-terminal (N-CTD). It also has 3 conserved regions (I, II, III) that are detached by A and $B$ regions. Region II is responsible for RNA binding $[64,65]$ while region III plays an important role in the binding of the M protein [57]. NTD domain begins from the conserved region I and ends with conserved region II. CTD domain is located inside the conserved region II and ends just before region $\mathrm{B}[66,67,68,69]$.

Cowely at al. investigated the role of the $\mathrm{N}$ protein in MHVinduced disease using the A59 and JHS strains described above. Their research was based on the fact that almost $95 \%$ of the amino acid level in the $\mathrm{N}$ proteins of those strains is identical. They used 2 chimeric viruses with the exchange of $\mathrm{N}$ proteins between the A59 and JHS strains, compared to the wild-strains. Surprisingly, no morphological changes were observed, but the observation focused on the virulence obviously satisfied their expectations, and statistically significant differences were noted in the replication in CNS. Moreover, the antigen expression in the brain was enhanced when the A59 chimera was used with the N protein from JHS [70].

The same chimera (rA59/NJHM) conferred enhanced virulence by an approximately 1,000-fold lower LD50 (Lethal Dose 50). In comparison, the chimera (rJHS/NA59) showed similar, but rather less results [70] This confirmed that the MHV antigen expression in the CNS consistently correlates with the virulence $[51,71]$.

Coronavirus receptors. The first and also essential step of the host cell infection is receptor recognition by the virus. As described above, the $\mathrm{S}$ protein is responsible for first binding to the specific receptor on the surface, and subsequently fusing with the host cell $[31,72]$. Another important step involves coronavirus RBD and its receptor. Understanding the receptor recognition mechanisms by CoVs seems to be crucial for human research against coronaviruses. The diversity of CoVs receptors are presented in Table 1.

Table 1. Coronaviruses fusion with the membrane and entry to the host cell

\begin{tabular}{|c|c|c|c|c|}
\hline Genera & $\mathrm{CoV}$ & Tropism & Receptor - Domain & Reference \\
\hline \multirow[t]{4}{*}{ a-genus } & NL63 & $\begin{array}{l}\text { alveolar cells type I and II, } \\
\text { endothelial cells, ciliated } \\
\text { bronchial cells }\end{array}$ & ACE2 - S1CTD & [40] \\
\hline & $229 E$ & $\begin{array}{l}\text { alveolar epithelial } \\
\text { cells type I, alveolar } \\
\text { macrophages }\end{array}$ & APN - S1CTD & {$[165,166]$} \\
\hline & TGEV & non-ciliated bronchial cells & $\begin{array}{l}\text { APN - S1CTD, sugar } \\
\text { - S1NTD }\end{array}$ & [74] \\
\hline & PRCoV & non-ciliated bronchial cells & APN - S1CTD & [74] \\
\hline \multirow[t]{7}{*}{$\beta$-genus } & OC43 & $\begin{array}{l}\text { epithelial and neuronal } \\
\text { cells }\end{array}$ & $\begin{array}{l}\text { 9-O-acetylated } \\
\text { sialic acid - S1NTD } \\
\text { domain A }\end{array}$ & {$[166,167]$} \\
\hline & HKU1 & $\begin{array}{l}\text { ciliated airway epithelial } \\
\text { cells, type II alveolar } \\
\text { epithelial cells }\end{array}$ & $\begin{array}{l}\text { 9-O-acetylated } \\
\text { sialic acid - S1NTD } \\
\text { domain A }\end{array}$ & {$[166,168]$} \\
\hline & MHV & $\begin{array}{l}\text { leukocytes, epithelia, and } \\
\text { endothelia cells }\end{array}$ & $\begin{array}{l}\text { CEACAM1 - S1NTD, } \\
\text { distal loops domain A }\end{array}$ & [41] \\
\hline & $\mathrm{BCoV}$ & non-enteric epithelial cells & $\begin{array}{l}\text { 9-O-acetylated } \\
\text { sialic acid- S1NTD } \\
\text { domain A }\end{array}$ & {$[75]$} \\
\hline & MERS & $\begin{array}{l}\text { endothelial cells, } \\
\text { endothelial tissues }\end{array}$ & $\begin{array}{l}\text { DPP4 - S1CTD, } \\
\beta \text {-motif, domain B }\end{array}$ & [39] \\
\hline & $\begin{array}{l}\text { SARS- } \\
\text { CoV-1 }\end{array}$ & $\begin{array}{l}\text { alveolar cells type I and II, } \\
\text { endothelial cells, ciliated } \\
\text { bronchial cells }\end{array}$ & $\begin{array}{l}\text { ACE2 - S1CTD, } \\
\beta \text {-motif, domain B }\end{array}$ & [37] \\
\hline & $\begin{array}{l}\text { SARS- } \\
\text { CoV-2 }\end{array}$ & $\begin{array}{l}\text { alveolar cells type I and II, } \\
\text { endothelial cells, ciliated } \\
\text { bronchial cells }\end{array}$ & $\begin{array}{l}\text { ACE2 - S1CTD, } \\
\beta \text {-motif, domain B }\end{array}$ & [37] \\
\hline Y-genus & IBV & epithelial cells & sugar - S1NTD & {$[75]$} \\
\hline
\end{tabular}


All the human CoVs receptors belong to the same family - membrane ectopeptidases. However, it has been shown that viral entry is not dependent on the catalytic activity of these enzymes. The crucial step is co-expression of other host peptidases [76, 77], e.g. human transmembrane serine proteases HAT and TMPRSSII are involved in the cleaving and activating of the MERS-CoVs and SARS-CoVs Spike proteins $[78,79]$.

Angiotensin Converting Enzyme 2 (ACE-2), the functional receptor for the spike glycoprotein of the human SARS-CoV, is a zinc-dependent mono-carboxypeptidase that catalyzes the cleavage of angiotensin [80]. It regulates cardiovascular function [81] and protects against severe acute lung failure [82]. ACE-2 is expressed on alveolar cells types I and II, endothelial cells, and also on ciliated bronchial cells [83].

Aminopeptidase N (APN), also known as CD13, is a zincdependent ectopeptidase that cleaves proteins peptides from $\mathrm{N}$-terminal amino acid. APN is a type II transmembrane protein associated with various functions, such as pain sensation, blood pressure regulation, cancer angiogenesis and metastasis, immune cell chemotaxis as well as cell-cell adhesion [84]. Two common CoVs are able to recognize APN: TGEV that infects cells of the small intestine and respiratory track, and PRCoV (Porcine Respiratory Coronavirus) that infects only pulmonary cells. The one and only difference between spikes of those strains is that the $S$ protein from TGEV has a haemagglutinating activity that enables TGEV to replicate in the gut [74]. APN is mostly expressed on nonciliated bronchus cells [85].

Carcinoembryonic Antigen-Related Cell Adhesion Molecule 1 (CEACAM1) is a cell adhesion molecule that occurs on leukocytes, epithelia, and endothelia. It is responsible for apoptosis, angiogenesis, tumour suppression, and the induction of immune responses $[86,87,88]$. However, it has been noted that the neurovirulence of the JHM strain correlates with the enhanced spread of the virus in the brain and not fully dependent on CEACAM1. Miura at al. demonstrated that ceacam1-/-mice could also be infect by the JHM strain, but with a 100-fold higher lethal dose [89].

Dipeptidyl Peptidase-4 (DPP4), a serine exoprotease, plays a multifunctional role in physiological processes by removing N-termini from many peptides, including hormones, neuropeptides, chemokines and mitogenic growth factors $[86,90]$. DPP4 is commonly expressed in endothelial cells as well as multiple epithelial tissues [91].

Finally, some coronaviruses, e.g. avian infectious bronchitis virus (IBV), bind sugars that play an essential role in a variety of biological processes, such as cell interactions or immunity $[92,93]$.

Unfortunately, those examples do not explain how coronaviruses are able to recognize their specific receptors. There are 6 representative structures composed of $S 1$ domains and its receptor: SARS-CoVs S1-CTD and ACE2 [37], MERSCoV S1-CTD and DPP4 [39,94] HCoV-NL63 S1-CTD and ACE2 [40], PRCoV S1-CTD and APN [95], MHV S1-NTD and CEACAM1 [41], OC43, HKU1, BCoV 9-O-acetylated sialic acid and S1-NTD [75] (Tab. 1).

There is no rule for the receptor recognition. CoVs from the same genera recognize different receptors, e.g., MERS-CoV and SARS-CoV belong to the $\beta$-genus, but their S1CTDs bind
DPP4 and ACE-2, respectively [96, 97]. Moreover, some CoVs from different genera are able to recognize the same receptor, e.g. although NL63-CoV belongs to a-genus and SARS-CoV belongs to $\beta$-genus, both S1-CTDs bind ACE-2 [98, 99, 100, $101,102,103,104]$. Finally, coronaviruses could use one or both S1 domains as RBDs, e.g., S1-CTD of TGEV-CoV binds APN, while its S1-NTD recognizes sugar [105].

It is well known that SARS-CoV mostly replicates in alveolar tissues, and is therefore commonly observed with pneumonia. On the other hand MERS-CoV has wide cellular tropism. It is able to replicate in both bronchial and alveolar tissue, and could therefore be the reason for such high mortality [106].

Coronavirus entry and entry into the host cell. After binding with specific receptors, enveloped viruses have the necessity to fuse with a host membrane, and subsequently deliver the viral genome to achieve successful infection. There are 2 main pathways. The first is $\mathrm{pH}$-independent, based on genome delivery to the cytosol, and subsequently the fusion of their envelopes with the plasma membrane. However, many viruses use receptor-dependent endocytosis as a way of viral entry. In this process, virions are endocytosed and surrendered to the crucial step which takes place in the endosomes. Environmental cues, such as $\mathrm{pH}$ decrease, changing of the redox status and proteolytic activity, are necessary for inducing conformational changes in viral proteins, and subsequently lead to fusion of viral envelope and endosomal host membranes. Finally, the viral positive-strand RNA genome is released into the cytoplasm [107, 108, 109, 110].

Cellular endocitosis of viral entry could induce clathrindependent, caveolae-dependent, clathrin-independent as well as caveolae-independent mechanisms [111, 112, 113]. SARS-CoV was at first thought to enter by direct fusion at the plasma membrane $[114,115,116]$. Further studies identified that low $\mathrm{pH}$ could have asignificant influence on this process [117], and an acid protease, cathepsin L could be involved $[118,116]$, which suggests that SARS-CoV could enter via endocytosis.

Many experiments have been carried out that have produced conflicting results. One of the most common pathways is the clathrin-dependent pasthway,based on viral entry and translocation into endosomes where they are degraded or recycled $[119,120]$. This pathway starts from binding the adaptor protein 2 (AP2) to the cytoplasmic tail of the receptors using clathrins $[121,122]$. The receptors are then invaginated to clathrin coated pits. Viruses connected with receptors are subsequently endocytosed and transported to early endosomes in a $\mathrm{pH}$-dependent way. Low $\mathrm{pH}$ is necessary to mature vesicles to late endosomes, and subsequently set up an infection $[111,112]$. Inoue at al. demonstrated that SARS-CoV binds ACE2 and penetrates endosomes in the clatrhrin-dependent mechanism. Spike protein is first cleaved into the $\mathrm{S} 1$ and $\mathrm{S} 2$ subdomains by cathepsin $\mathrm{L}$. This process provides the fusion of the viral envelope and the membrane of the endosome. Clattern-coated pits are shaped because of the contact between the AP2 with the clathrin complex and ACE2 with the virus, which is finally translocated to edosomes. Uncoating of the virus is made by acid protease, e.g. cathepsin L [119].

Further studies demonstrated that there is also a caveolaedependent pathway. Caveolae are a flask-shaped type of lipid 
rafts. These small invaginations of the plasma membrane are composed of cholesterol, glycophingolipids and caveolin [123]. Caveolin is able to oligomerize which leads to the formation of caveolin-rich microdomains in the plasma membrane, and subsequently to the endocytic vesicle. The released caveolar vesicle has gained the ability to fuse with the early endosomal compartment - caveosome or even endosome [124]. Choi at al. demonstrated on the MHV strain that lipid rafts must have been involved in virus entry to the host cell and also in cell-cell fusion [123], but to-date there is no data about the host lipid modulation by CoVs [125].

The current study concerned the inventory of pro- and antiviral host factors relevant for SARS-CoV replication. Using siRNA (small interfering RNAs), de Wilde et al. demonstrated that over 40 proteins, including molecules involved in lipid metabolism, promote SARS-CoV replication. They found that depletion of double-stranded RNA-activated protein kinase (PKR) promotes increased SARS-CoV protein expression. Moreover, cyclin-dependent kinase 6 (CDK6) was identified as a novel anti-viral host factor in SARS-CoV replication [126].

Wang at al. confirmed that CoVs could also infect cells in a clathrin- and caveolae-independent mechanism. This concerned especially CoVs that harbur a non-cleaved spike on their surface. Wang at al. discovered that SARS-CoV is able enter to cells by a $\mathrm{pH}$-sensitive pathway in the absence of clathrin-mediated endocytosis [127]. Indeed, because of the low $\mathrm{pH}$, SARS-CoV infection can be inhibited by lysomotropic agents [128]. Thus, SARS-CoV fusion could probably be triggered by proteolytic processing of the spike. It has been proved in vitro that SARS-CoV infection is enhanced by a diversity of proteins, such as elastase, thermolysin or trypsin [129], which trigger fusion by dual cleavage: between S1 and S2 together, as well as at the N-terminal of the fusion peptide $[130,131,132]$.

Another research investigated the endo- and lysosomal pathway in a proteolysis-dependent manner. Using siRNA, the investigators demonstrated that strain A59 of MHV-CoV requires proteins for the maturation of the endosome, and its subsequent fusion with lysosome during cell infection. They confirmed that MHV entry is dependent upon clathrinmediated endocytosis by using replication-independent fusion assay and the MHV particles fuse in lysosomes. They hypothesized that the fusion site is determined by the proteolytic cleavage site, upstream of the FP in the spike protein [107].

Conducted studies demonstrated that viruses could use more than one pathway to enter into the host cell [133, 134]. Over the years, coronaviruses have altered their $S$ proteins, which leads to the variety of the fusion mechanisms depending on the strain. It remains unclear how $\mathrm{CoV}$ s choose the way of entry. After binding with a specific receptor, fusion might appear at the cell surface or after endocytosis. Preferred entry could also be dependent on the cell type and $\mathrm{pH}$ acidification.

Membrane rearrangements. During the infection in mammalian cells, coronaviruses rearrange cellular membranes into organelle-like replicative structures including double-membrane vesicles (DMVs) and convoluted membranes (CMs). DMVs range vary from 150-300 nm [135]. Nsp3, nsp4 and nsp6 are believed to structure the DMV formation and subsequently attach the RTC to intracellular membranes [17, 136, 137, 138]. RTC is constructed through the interplay of the $16 \mathrm{CoVs}$ non-structural proteins and as well as the $\mathrm{N}$ protein [137].

Coronaviruses also induce a wide range of membrane structures, some of which are responsible for viral RNA synthesis, such as DMVs and CMs. DMVs are present in a very high proportion in the perinuclear region of cytoplasm. CMs are present between the clusters of DMVs [139, 140, 141]. Many studies hale demonstrated that DMVs do not remain isolated vesicles, but an interconnected membranous network continuous with Endoplasmic Reticulum (ER) [139]. Electron tomography studies confirmed that those replicative structures are localized in MHV-CoV and SARS-CoVs nps. $[136,142,139,140,143,144]$. However, CMs are more highly enriched in SARS-CoV nsps than DMVs [139]. Therefore, it is though that active replicase complex is localized to the CM [145].

Immunoelectron microscopy has shown that newly synthesized viral RNA was present near the replicative structures described above $[146,147]$. Later, CoVs generate Large Virion-Containing Vesicles (LVCVs), Tubular Bodies (TBs) and also Cubic Membrane Structures (CMSs) [114, 139, $140,148]$. Subsequently, at later stages of SARS-CoV infection, DMVs are believed to fuse into packets of single-membrane vesicles surrounded by a common outer membrane, and the clustered single DMVs slowly disappeared. Those Vesicle Packets (VPs) are quite large $(1-5 \mu \mathrm{m})$ and tend to include over 25 inner vesicles $[139,148]$. However, electron tomography has not revealed any connections between the interior of DMVs and the cytosol. This finding leads to the hypothesis that the replication carries out in DMVs until the network with the cytosol is maintained [145].

It remains unclear where nascent viral RNA synthesis take place. Although nps include DMVs and CMs, the connection with the cytoplasm has not yet been detected. The presence of viral enzymes involved in RNA synthesis is not equal to active RTCs. Sites of RNA synthesis certainly include RdRp, dsRNA, as well as nascent viral RNA. The latter has been visualized close to antibodies that recognize nsp5 and the C-terminal end of ppla [147]. Further studies demonstrated that newly-synthesized coronaviral RNA were observed in MHV-infected cells in the vicinity of DMVs [149]. Furthermore, nascent viral RNA was also observed in close proximity to nsp12 that contains RdRp [135].

However, during later stages of CoVs infection, not all DMVs remain active and are not involved in RNA synthesis. Moreover, those which persist actively, frequently enclose small quantities of dsRNA. Another credible site for RNA synthesis seems to be CMs [135]. Therefore, further studies must be undertaken to accurately determine the localization of CoVs RNA synthesis, as well as the exact composition of the RTCs.

Reticulovesicular Network (RVN) is a part of a membrane associated with the virus replication. Many studies have suggested that ER could be involved in the biogenesis of this compartment $[150,151]$. It has been shown that the Endoplasmic-Reticulum Associated protein Degradation (ERAD) is connected with CoVs replicative structures [152]. On the other hand, there are many membrane proteins, such as Sec13, Arf1, GBF1 or synaxin 5 that have not been detected in $\mathrm{RVN}$, despite functioning downstream of the ER in the secretory pathway. 
Treatment of CoVs infections. Despite many scientific studies on human CoVs, there is currently no efficient therapy available. Commonly, patients are treated ineffectively with interferon or/and ribavirin [153, 154, 155, 156, 157]. The treatment with IFN alpha or lambda is only reasonable for the preventive treatment of exposed people. The rise of newer and more acute CoVs has emphasized the demand to develop effective therapeutic tools against CoVs. Therefore it highlights the need to discover an effective therapeutic tool against CoVs.

Over the years, e a wide range of molecules have been determined against coronaviruses, i.e. protease inhibitors $[158,159,160]$. Lundin at al. screened a collection of 1,6671 varied compounds against human CoVs and identified an inhibitor, designated $\mathrm{K} 22$, which specifically targets membrane-bound RNA synthesis. It proved to be efficient in primary human epithelia cultures against a wide spectrum of human coronaviruses, including MERS. K22 expend the most effective antiviral activity at an early step of the viral life cycle [161].

The ideal target of vaccinology seems to be the accessibility of the conservation sequence of the fusion peptide at the periphery of the trimer [54]. Studies may be based on raising neutralizing antibodies of CoVs $\mathrm{S}$ proteins, which overlap with the fusion peptide [162]. Antigenic determinants that binds to this conserved site could block the insertion of the fusion peptide into target membrane, and also prevent conformational changes [54].

Sme trials conducted on Spike proteins have achieved in vivo a therapeutic threshold, i.e. against SARS [163] or MERS [164], which suggests that it might be possible to discover a vaccine against human CoVs.

\section{CONCLUSIONS}

Coronaviruses has the largest RNA plus strand genome which encodes a variety of RNA-modifying enzymes, often absent in most virus strains. Many studies hale demonstrated that the spike protein is the crucial molecule responsible for CoVs tropism and cell entry. Recent research has shown that modifications of the $S$ protein could effect the viral pathogenicity. The development of host-directed antiviral therapy seems to be promising way to treat infections with SARS-CoV or other pathogenic coronaviruses. There is still much to be discovered in the inventory of pro- and antiviral host factors relevant for CoVs replication. Therefore, studies on coronaviruses have a significant impast on health and the economy. Further research on the interactions between coronaviruses proteins in viral replication may also be of appreciable importance.

\section{REFERENCES}

1. Rehman SU, Shafique L, Ihsan A, Liu Q. Evolutionary Trajectory for the Emergence of Novel Coronavirus SARS-CoV-2. Pathogens 2020; $23,9(3)$.

2. de Wilde AH, Snijder EJ, Kikkert M, van Hemert MJ. Host Factors in Coronavirus Replication. In: Tripp R, Tompkins S. (eds) Roles of Host Gene and Non-coding RNA Expression in Virus Infection. Current Topics in Microbiology and Immunology Springer, Cham. 2017; 419: 1-42.

3. Hudson CB, Beaudette FR. Infection of the cloaca with the virus of infectious bronchitis. Science 1932; 76, 34
4. Peiris JSM, Guan Y, Yuen KY. Severe acute respiratory syndrome. Nat Med. 2004; 10: 88-97.

5. Yang D, Leibowitz JL. The structure and functions of coronavirus genomic 3' and 5' ends. Virus Res. 2015; 206: 120-133.

6. Peiris JSM, Lai ST, Poon LLM, Guan Y, Yam LYC, Lim W, et al. Coronavirus as a possible cause of severe acute respiratory syndrome. Lancet 2003; 361: 1319-1325.

7. Rota PA, Oberste MS, Monroe SS, Nix WA, Campagnoli R, Icenogle JP, et al. Characterization of a novel coronavirus associated with severe acute respiratory syndrome. Science. 2003; 300: 1394-1399.

8. World-Health-Organization Update 49 - SARS case fatality ratio, incubation period. https:/www.who.int/csr/don/4-december-2015mers-saudi-arabia/en/ (accessed:2020.04.02).

9. COVID-19 coronavirus pandemic. Available online: https://www. worldometers.info/coronavirus/ (accessed: 2020.04.02).

10. Perlman S, Netland J. Coronaviruses post-SARS: update on replication and pathogenesis. Nat Rev Microbiol. 2009; 7: 439-450.

11. Enjuanes L, Almazan F, Sola I, Zuniga S. Biochemical aspects of coronavirus replication and virus-host interaction. Annu Rev Microbiol. 2006; 60: 211-230.

12. Dong S, Sun J, Mao Z, Wang L, Lu Y-L, Li J. A guideline for homology modeling of the proteins from newly discovered betacoronavirus, 2019 novel coronavirus (2019-nCoV). J Med Virol. 2020; 1-7.

13. Viehweger A, Krautwurst S, Lamkiewicz K, Madhugiri R, Ziebuhr J, Holzer M, Marz M. Direct RNA nanopore sequencing of full-length coronavirus genomes provides novel insights into structural variants and enables modification analysis. Genome Res. 2019; 29: 1545-1554.

14. Zuniga S, Sola I, Alonso S, Enjuanes L. Sequence motif involved in the regulation of discontinuous coronavirus subgenomic RNA synthesis. J Virol. 2004; 78: 980-994.

15. Sawicki SG, Sawicki DL, Siddell SG. A contemporary view of coronavirus transcription. J Virol. 2007; 81: 20-29.

16. Srinivasan S, Cui H, Gao Z, Liu M, Lu S, Mkandawire W, Narykov O, Sun M, Korkin D. Structural Genomics of SARS-CoV-2 Indicates Evolutionary Conserved Functional Regions of Viral Proteins. Viruses. 2020; 12(4): 360 .

17. Oostra M, Te Lintelo E, Deijs M, Verheije M, Rottier P, de Haan C. Localization and membrane topology of coronavirus nonstructural protein 4: Involvement of the early secretory pathway in replication. J Virol. 2007; 81: 12323-12336.

18. Baliji S, Cammer SA, Sobral B, Baker SC. Detection of nonstructural protein 6 in murine coronavirus-infected cells and analysis of the transmembrane topology by using bioinformatics and molecular approaches. J Virol. 2009; 83: 6957-6962.

19. Belouzard S, Millet JK, Licitra BN, Whittaker GR. Mechanisms of coronavirus cell entry mediated by the viral spike protein. Viruses 2012; 4: 1011-1033.

20. Du LY, He YX, Zhou YS, Liu SW, Zheng BJ, Jiang SB. The spike protein of SARS-CoV-a target for vaccine and therapeutic development. Nat Rev Microbiol. 2009; 7: 226-236.

21. Jaimes JA, Whittaker GR. Feline coronavirus: Insights into viral pathogenesis based on the spike protein structure and function. Virology 2018; 517: 108-121.

22. Duquerroy S, Vigouroux A, Rottier PJ, Rey FA, Bosch BJ. Central ions and lateral asparagine/glutamine zippers stabilize the post-fusion hairpin conformation of the SARS coronavirus spike glycoprotein. Virology 2005; 335: 276-285.

23. Gao J, Lu G, Qi J, Li Y, Wu Y, Deng Y, et al. Structure of the fusion core and inhibition of fusion by a heptad repeat peptide derived from the $S$ protein of Middle East respiratory syndrome coronavirus. J Virol. 2013; 87: 13134-13140.

24. Walls A, Tortorici M, Bosch B. Frenz B, Rottier P, et al. Cryo-electron microscopy structure of a coronavirus spike glycoprotein trimer. Nature 2016; 531: 114-117.

25. Skehel JJ, Wiley DC. Receptor binding and membrane fusion in virus entry: the influenza hemagglutinin. Annu Rev Biochem. 2000; 69: 531-569.

26. Wilson IA, Skehel JJ, Wiley DC. Structure of the haemagglutinin membrane glycoprotein of influenza virus at 3 A resolution. Nature. 1981; 289: 366-373.

27. Eckert DM, Kim PS. Mechanisms of viral membrane fusion and its inhibition. Annu Rev Biochem. 2001; 70: 777-810.

28. Harrison SC. Viral membrane fusion. Nat Struct Mol Biol. 2008; 15: 690-698.

29. Li F, Berardi M, Li WH, Farzan M, Dormitzer PR, Harrison SC. Conformational states of the severe acute respiratory syndrome coronavirus spike protein ectodomain. J Virol. 2006; 80: 6794-6800. 
30. Beniac DR, Andonov A, Grudeski E, Booth TF. Architecture of the SARS coronavirus prefusion spike. Nat Struct Mol Biol. 2006; 13: 751-752.

31. Bosch BJ, van der Zee R, de Haan CA, Rottier PJ. The coronavirus spike protein is a class I virus fusion protein: Structural and functional characterization of the fusion core complex. JVirol. 2003; 77: 8801-8811.

32. Du L, Zhao G, Yang Y, Qiu H, Wang L, Kou, Z, et al. A conformationdependent neutralizing monoclonal antibody specifically targeting receptor binding domain in Middle East respiratory syndrome coronavirus spike protein. J Virol. 2014; 88: 7045-7053.

33. Zhou H, Chen Y, Zhang S, Niu P, Qin K, et al. Structural definition of a neutralization epitope on the N-terminal domain of MERS-CoV spike glycoprotein. Nat Commun 2019; 10: 3068.

34. Ying T, Du L, Ju TW, Prabakaran P, Lau CC, Lu L, et al. Exceptionally potent neutralization of Middle East respiratory syndrome coronavirus by human monoclonal antibodies. J Virol. 2014; 88: 7796-7805.

35. Jiang L, Wang N, Zuo T, Shi X, Poon KM, Wu Y, et al. Potent neutralization of MERS-CoV by human neutralizing monoclonal antibodies to the viral spike glycoprotein. Sci Transl Med. 2014; 6: 234 ra59.

36. Walls A, Park Y, Tortorici M, Wall A, McGuire A, et al. Structure, Function, and Antigenicity of the SARS-CoV-2 Spike Glycoprotein, Cell 2020; 180: 1-12.

37. Hoffmann M, Kleine-Weber H, Schroeder S, Krüger N, Herrler T, et al. ARS-CoV-2 Cell Entry Depends on ACE2 and TMPRSS2 and Is Blocked by a Clinically Proven Protease Inhibitor. Cell 2020; https:// doi.org/10.1016/j.cell.2020.02.052

38. Li F, Li WH, Farzan M, Harrison SC. Structure of SARS coronavirus spike receptor-binding domain complexed with receptor. Science 2005; 309: 1864-1868.

39. Lu G, Hu Y, Wang Q, Qi J, Gao F, Li Y, et al. Molecular basis of binding between novel human coronavirus MERS-CoV and its receptor CD26. Nature 2013; 500: 227-231.

40. Wu K, Li WB, Peng G, Li F. Crystal structure of NL63 respiratory coronavirus receptor-binding complexed with its human receptor. Proc Natl Acad Sci. USA. 2009; 106: 19970-19974.

41. Peng GQ, Sun DW, Rajashankar KR, Qian ZH, Holmes KV, Li F. Crystal structure of mouse coronavirus receptor-binding domain complexed with its murine receptor. Proc Natl Acad Sci. USA. 2011; 108: 10696-10701.

42. Casais R, Dove B, Cavanagh D, Britton P. Recombinant avian infectious bronchitis virus expressing a heterologous spike gene demonstrates that the spike protein is a determinant of cell tropism. J Virol. 2003; 9084-9089.

43. van Beurden, S, Berends, A, Krämer-Kühl, A, Spekreijse D, Philipp $\mathrm{H}$, et al. A reverse genetics system for avian coronavirus infectious bronchitis virus based on targeted RNA recombination. Virol J. 2017; 14: 109.

44. Darbyshire JH, Rowell JG, Cook JKA, Peters RW. Taxonomic studies on strains of avian infectious bronchitis virus using neutralisation tests in tracheal organ cultures. Arch Virol. 1979; 61: 227-238.

45. Godeke GJ, de Haan CA, Rossen JW, Vennema H, Rottier PJ. Assembly of spikes into coronavirus particles is mediated by the carboxyterminal domain of the spike protein. J Virol. 2000; 74: 1566-1571.

46. Gombold JL, Sutherland RM, Lavi E, Paterson Y, Weiss SR. Mouse hepatitis virus A59-induced demyelination can occur in the absence of CD8 T cells. Microb Pathog. 1995; 18: 211-221.

47. Lavi E, Gilden DH, Highkin MK, Weiss SR. Persistence of mouse hepatitis virus A59 RNA in a slow virus demyelinating infection in mice as detected by in situ hybridization. J Virol. 1984; 51: 563-566.

48. Matthews AE, Weiss SR, Paterson Y. Murine hepatitis virus-a model for virus-induced CNS demyelination. J Neurovirol. 2002; 8: 76-85.

49. Navas S, Seo SH, Chua MM, Das Sarma J, Lavi E, Hingley ST, et al. Murine coronavirus spike protein determines the ability of the virus to replicate in the liver and cause hepatitis. J Virol. 2001; 75: 2452-2457.

50. Navas S, Weiss SR. Murine coronavirus-induced hepatitis: JHM genetic background eliminates A59 spike-determined hepatotropism. J Virol. 2003; 77: 4972-4978

51. Iacono KT, Kazi L, Weiss SR. Both spike and background genes contribute to murine coronavirus neurovirulence. J Virol. 2006; 80: 6834-6843

52. MacNamara KC, Chua MM, Phillips JJ, Weiss SR. Contributions of the viral genetic background and a single amino acid substitution in an immunodominant CD8 T-cell epitope to murine coronavirus neurovirulence. J Virol. 2005; 79: 9108-9118.

53. Phillips, JJ, Chua MM, Lavi E, Weiss SR. Pathogenesis of chimeric MHV4/MHV-A59 recombinant viruses: the murine coronavirus spike protein is a major determinant of neurovirulence. J Virol. 1999; 73: 7752-7760.

54. Walls AC, Tortorici MA, Bosch BJ, Frenz B, Rottier PJ, DiMaio F, et al. Cryo-electron microscopy structure of a coronavirus spike glycoprotein trimer Nature. 2016; 531: 114-117.

55. Shang J, Zheng Y, Yang Y, Liu C, Geng Q, Tai W, et al. Cryo-electron microscopy structure of porcine deltacoronavirus spike protein in the prefusion state, J Virol. 2018; 92(4): e01556-17.

56. Jaimes JA, Whittaker GR, Feline coronavirus: Insights into viral pathogenesis based on the spike protein structure and function. Virol. 2018; 517: 108-121.

57. Hurst KR, Kuo L, Koetzner CA, Ye R, Hsue B, Masters PS. A major determinant for membrane protein interaction localizes to the carboxy-terminal domain of the mouse coronavirus nucleocapsid protein. J Virol. 2005; 79: 13285-13297.

58. Baric RS, Nelson GW, Fleming JO, Deans RJ, Keck JG, Casteel N, et al. Interactions between coronavirus nucleocapsid protein and viral RNAs: implications for viral transcription. J Virol. 1988; 62: 4280-4287.

59. Pasick JM, Kalicharran K, Dales S. Distribution and trafficking of JHM coronavirus structural proteins and virions in primary neurons and the OBL-21 neuronal cell line. J Virol. 1994; 68: 2915-2928.

60. Ye Y, Hauns K, Langland JO, Jacobs BL, Hogue BG. Mouse hepatitis coronavirus A59 nucleocapsid protein is a type I interferon antagonist. J Virol. 2007; 81: 2554-2563.

61. Ding JW, Ning Q, Liu MF, Lai A, Peltekian K, Fung L, et al. Expression of the fgl2 and its protein product (prothrombinase) in tissues during murine hepatitis virus strain-3 (MHV-3) infection. Adv Exp Med Biol. 1998; 440: 609-618.

62. Fan H, Ooi A, Tan YW, Wang S, Fang S, Liu DX, et al. The nucleocapsid protein of coronavirus infectious bronchitis virus: crystal structure of its N-terminal domain and multimerization properties. Structure 2005; 13: 1859-1868.

63. Ning Q, Liu M, Kongkham P, Lai MM, Marsden PA, Tseng J, et al. The nucleocapsid protein of murine hepatitis virus type 3 induces transcription of the novel fgl 2 prothrombinase gene. J Biol Chem. 1999; 274: 9930-9936.

64. Zhang X, Zhao X, Dong H, et al. Characterization of Two Monoclonal Antibodies That Recognize Linker Region and Carboxyl Terminal Domain of Coronavirus Nucleocapsid Protein. PLoS One. 2016; 11(9): e0163920.

65. Nelson GW, Stohlman SA. Localization of the RNA-binding domain of mouse hepatitis virus nucleocapsid protein. J Gen Virol. 1993; 74: 1975-1979.

66. Huang Q, Yu L, Petros AM, Gunasekera A, Liu Z, Xu N, et al. Structure of the N-terminal RNA-binding domain of the SARS CoV nucleocapsid protein. Biochemistry, 2004; 43: 6059-6063.

67. Jayaram H, Fan H, Bowman BR, Ooi A, Jayaram J, Collisson EW, et al. $\mathrm{X}$-ray structures of the $\mathrm{N}$ - and C-terminal domains of a coronavirus nucleocapsid protein: implications for nucleocapsid formation. JVirol. 2006; 80: 6612-6620.

68. Saikatendu KS, Joseph JS, Subramanian V, Neuman BW, Buchmeier MJ, Stevens RC, et al. Ribonucleocapsid formation of severe acute respiratory syndrome coronavirus through molecular action of the N-terminal domain of N protein. J Virol. 2007; 81: 3913-3921.

69. Yu IM, Oldham ML, Zhang J, Chen J. Crystal structure of the severe acute respiratory syndrome (SARS) coronavirus nucleocapsid protein dimerization domain reveals evolutionary linkage between Coronaviridae and Arteriviridae. J Biol Chem 2006; 281: 17134-17139.

70. Cowley TJ, Long SY, Weiss SR. The murine coronavirus nucleocapsid gene is a determinant of virulence. J Virol. 2010; 84: 1752-1763.

71. Phillips JJ, Chua MM, Rall GF, Weiss SR. Murine coronavirus spike glycoprotein mediates degree of viral spread, inflammation, and virusinduced immunopathology in the central nervous system. Virology 2002; 301: 109-120.

72. Spaan W, Cavanagh D, Horzinek MC. Coronaviruses: structure and genome expression. J Gen Virol. 1988; 69: 2939-2952.

73. Li F. Receptor recognition mechanisms of coronaviruses: a decade of structural studies. J Virol. 2015; 89: 1954-1964.

74. Schultze B, Krempl C, Ballesteros ML, Shaw L, Schauer R, Enjuanes $\mathrm{L}$, et al. Transmissible gastroenteritis coronavirus, but not the related porcine respiratory coronavirus, has a sialic acid ( $\mathrm{N}$-glycolylneuraminic acid) binding activity. J Virol. 1996; 70: 5634-5637.

75. Peng GQ, Xu LQ, Lin YL, Chen L, Pasquarella JR, Holmes KV, et al. Crystal structure of bovine coronavirus spike protein lectin domain. J Biol Chem. 2012; 287: 41931-41938.

76. Bosch BJ, Smits SL, Haagmans B. Membrane ectopeptidases targeted by human coronaviruses. Curr Opin Virol. 2014; 6: 55-60. 
77. Heald-Sargent T, Gallagher T. Ready, set, fuse! The coronavirus spike protein and acquisition of fusion competence. Viruses. 2012; 4: $557-80$

78. Bertram S, Dijkman R, Habjan M, Heurich A, Gierer S, Glowacka I, et al. TMPRSS2 activates the human coronavirus 229E for cathepsinindependent host cell entry and is expressed in viral target cells in the respiratory epithelium. J Virol. 2013; 87: 6150-60.

79. Glowacka I, Bertram S, Muller MA, Allen P, Soilleux E, Pfefferle S, et al. Evidence that TMPRSS2 activates the severe acute respiratory syndrome coronavirus spike protein for membrane fusion and reduces viral control by the humoral immune response. J Virol. 2011; 85 : 4122-34.

80. Towler P, Staker B, Prasad SG, Menon S, Tang J, Parsons T, et al. X-ray structures reveal a large hinge-bending motion important for inhibitor binding and catalysis. J Biol Chem. 2004; 279: 17996-18007.

81. Keidar S, Kaplan M, Gamliel-Lazarovich A. ACE2 of the heart: from angiotensin I to angiotensin (1-7). Cardiovasc Res. 2007; 73: 463-469.

82. Kuba K, Imai Y, Rao SA, Gao H, Guo F, Guan B, et al. A crucial role of angiotensin converting enzyme 2 (ACE2) in SARS coronavirusinduced lung injury. Nat Med. 2005; 11: 875-879.

83. Hamming I, Timens W, Bulthuis ML, Lely AT, Navis G, van Goor $\mathrm{H}$. Tissue distribution of ACE2 protein, the functional receptor for SARS coronavirus. A first step in understanding SARS pathogenesis. J Pathol. 2004; 203: 631-7.

84. Mina-Osorio P. The moonlighting enzyme CD13: old and new functions to target. Trends Mol Med. 2008; 14: 361-371.

85. van der Velden VH, Wierenga-Wolf AF, Adriaansen-Soeting PW, Overbeek SE, Moller GM, Hoogsteden HC, et al. Expression of aminopeptidase $\mathrm{N}$ and dipeptidyl peptidase IV in the healthy and asthmatic bronchus. Clin Exp Allergy. 1998; 28: 110-20.

86. Tan KM, Zelus BD, Meijers R, Liu JH, Bergelson JM, Duke N, et al. Crystal structure of murine sCEACAM1a 1,4: a coronavirus receptor in the CEA family. EMBO J. 2002; 21: 2076-2086.

87. Beauchemin N, Draber P, Dveksler G, Gold P, Gray-Owen S, Grunert $\mathrm{F}$, et al. Redefined nomenclature for members of the carcinoembryonic antigen family. Exp Cell Res. 1999; 252: 243-249.

88. Hammarström S. The carcinoembryonic antigen (CEA) family: structures, suggested functions and expression in normal and malignant tissues. Semin. Cancer Biol. 1999; 9: 67-81.

89. Miura TA, Travanty EA, Oko L, Bielefeldt-Ohmann H, Weiss SR, Beauchemin N, et al. The spike glycoprotein of murine coronavirus MHV-JHM mediates receptorindependent infection and spread in the central nervous systems of Ceacamla-/- Mice. J Virol. 2008; 82: 755-763.

90. Kameoka J, Tanaka T, Nojima Y, Schlossman SF, Morimoto C. Direct association of adenosine deaminase with a $\mathrm{T}$ cell activation antigen, CD26. Science 1993; 261: 466-469.

91. Lambeir AM, Durinx C, Scharpe S, De Meester I. Dipeptidyl-peptidase IV from bench to bedside: an update on structural properties, functions, and clinical aspects of the enzyme DPP IV. Crit Rev Clin Lab Sci. 2003; 40: 209-94.

92. Dove A. The bittersweet promise of glycobiology. Nat Biotechnol. 2001; 19: 913-917.

93. Ghazarian H, Idoni B, Oppenheimer SB. A glycobiology review: carbohydrates, lectins and implications in cancer therapeutics. Acta Histochem. 2011; 113: 236-247.

94. Wang N, Shi X, Jiang L, Zhang S, Wang D, Tong P, et al. Structure of MERS-CoV spike receptor-binding domain complexed with human receptor DPP4. Cell Res. 2013; 23: 986-993.

95. Reguera J, Santiago C, Mudgal G, Ordono D, Enjuanes L, Casasnovas JM. Structural bases of coronavirus attachment to host aminopeptidase $\mathrm{N}$ and its inhibition by neutralizing antibodies. PLoS Pathog. 2012; 8: e1002859.

96. Raj VS, Mou HH, Smits SL, Dekkers DHW, Muller, MA, Dijkman R. Dipeptidyl peptidase 4 is a functional receptor for the emerging human coronavirus-EMC. Nature 2013; 495: 251-254.

97. Du L, Zhao G, Kou Z, Ma C, Sun S, Poon VK, et al. Identification of a receptor-binding domain in the $S$ protein of the novel human coronavirus Middle East respiratory syndrome coronavirus as an essential target for vaccine development. J Virol. 2013; 87: 9939-9942.

98. Hofmann H, Pyrc K, van der Hoek L, Geier M, Berkhout B, Pohlmann S. Human coronavirus NL63 employs the severe acute respiratory syndrome coronavirus receptor for cellular entry. Proc Natl Acad Sci USA. 2005; 102: 7988-7993.

99. Li WH, Moore MJ, Vasilieva N, Sui JH, Wong SK, Berne MA, et al. Angiotensin-converting enzyme 2 is a functional receptor for the SARS coronavirus. Nature 2003; 426: 450-454.
100. Wong SK, Li WH, Moore MJ, Choe H, Farzan M. A 193-amino acid fragment of the SARS coronavirus S protein efficiently binds angiotensin-converting enzyme 2. J Biol Chem. 2004; 279: 3197-3201.

101. Lin HX, Fen Y, Wong G, Wang LP, Li B, Zhao XS, et al. Identification of residues in the receptor-binding domain (RBD) of the spike protein of human coronavirus NL63 that are critical for the RBD-ACE2 receptor interaction. J Gen Virol. 2008; 89: 1015-1024.

102. Hofmann H, Simmons G, Rennekamp AJ, Chaipan C, Gramberg T, Heck E, et al. Highly conserved regions within the spike proteins of human coronaviruses 229E and NL63 determine recognition of their respective cellular receptors. J Virol. 2006; 80: 8639-8652.

103. Babcock GJ, Esshaki DJ, Thomas WD, Ambrosino DM. Amino acids 270 to 510 of the severe acute respiratory syndrome coronavirus spike protein are required for interaction with receptor. J Virol. 2004; 78: $4552-4560$.

104.Xiao XD, Chakraborti S, Dimitrov AS, Gramatikoff K, Dimitrov DS. The SARS-CoV S glycoprotein: expression and functional characterization. Biochem Biophys Res Commun. 2003; 312: 1159-1164.

105. Delmas B, Gelfi J, Lharidon R, Vogel LK, Sjostrom H, Noren O, et al. Aminopeptidase- $\mathrm{N}$ is a major receptor for the enteropathogenic coronavirus TGEV. Nature 1992; 357: 417-420.

106. Chan RW, Chan MC, Agnihothram S, Chan LL, Kuok DI, Fong JH, et al. Tropism of and innate immune responses to the novel human betacoronavirus lineage $\mathrm{C}$ virus in human ex vivo respiratory organ cultures. J Virol. 2013; 87: 6604-14.

107. Burkard C, Verheije MH, Wicht O, van Kasteren SI, van Kuppeveld FJ, Haagmans BL, et al. Coronavirus cell entry occurs through the Endo-/Lysosomal pathway in a proteolysis-dependent manner, PLoS Pathog, 2014; 10: e1004502.

108. Authier F, Posner BI, Bergeron JJ. Endosomal proteolysis of internalized proteins. FEBS letters 1996; 389: 55-60.

109. Huotari J, Helenius A. Endosome maturation. EMBO. 2011; 30: 3481-3500.

110. Plemper RK. Cell entry of enveloped viruses. Curr Opin Virol. 2011; 1: $92-100$.

111. Marsh M, Helenius A. Virus entry: open sesame. Cell. 2006; 124: 729-740.

112. Pelkmans L, Helenius A. Insider information: what viruses tell us about endocytosis. Curr Opin Cell Biol. 2003; 15: 414-422.

113. Sieczkarski SB, Whittaker GR. Dissecting virus entry via endocytosis. J Gen Virol. 2002; 83: 1535-1545.

114. Ng ML, Tan SH, See EE, Ooi EE, Ling AE. Early events of SARS coronavirus infection in vero cells. J Med Virol. 2003; 71: 323-331.

115. Qinfen Z, Jinming C, Xiaojun H, Huanying Z, Jicheng H Ling F, et al. The life cycle of SARS coronavirus in Vero E6 cells. J Med Virol. 2004; 73: 332-337.

116. Simmons G, Reeves JD, Rennekamp AJ, Amberg SM, Piefer AJ, Bates $P$. Characterization of severe acute respiratory syndromeassociated coronavirus (SARS-CoV) spike glycoprotein-mediated viral entry. Proc Natl Acad Sci USA. 2004; 101: 4240-4245.

117. Yang ZY, Huang Y, Ganesh L, Leung K, Kong WP, Schwartz O, et al. $\mathrm{pH}$-dependent entry of severe acute respiratory syndrome coronavirus is mediated by the spike glycoprotein and enhanced by dendritic cell transfer through DC-SIGN. J Virol. 2004; 78: 5642-5650.

118. Huang IC, Bosch BJ, Li F, Lee KH, Ghiran S, Vasilieva N, et al. SARS coronavirus, but not human coronavirus NL63, utilizes cathepsin L to infect ACE2-expressing cells. J Biol Chem. 2006; 281: 3198-3203.

119. Inoue Y, Tanaka N, Tanaka Y, Inoue S, Morita K, Zhuang M, et al. Clathrin-dependent entry of severe acute respiratory syndrome coronavirus into target cells expressing ACE2 with the cytoplasmic tail deleted. J Virol. 2007; 81: 8722-8729.

120. Sieczkarski SB, Whittaker GR. Characterization of the host cell entry of filamentous influenza virus. Arch Virol. 2005; 150: 1783-1796.

121. Pearse BM, Smith CJ, Owen DJ. Clathrin coat construction in endocytosis. Curr Opin Struct Biol. 2000; 10: 220-228.

122. Sorkin A. Cargo recognition during clathrin-mediated endocytosis: a team effort. Curr Opin Cell Biol. 2004; 16: 392-399.

123. Choi KS, Aizaki H, Lai MM. Murine coronavirus requires lipid rafts for virus entry and cell-cell fusion but not for virus release. J Virol. 2005; 79: 9862-9871.

124. Sieczkarski SB, Whittaker GR. Influenza virus can enter and infect cells in the absence of clathrin-mediated endocytosis. J Virol. 2002; 76: 10455-10464.

125. Heaton NS, Randall G. Multifaceted roles for lipids in viral infection. Trends Microbiol. 2011; 19: 368-375.

126.De Wilde AH, Wannee KF, Scholte FE, Goeman JJ, Ten Dijke P, Snijder EJ, et al. Small interfering RNA screen identifies proviral and 
antiviral host factors in severe acute respiratory syndrome coronavirus replication, including double-stranded RNA-activated protein kinase and early secretory pathway proteins. J Virol. 2015; 89: 8318-8333.

127. Wang H, Yang P, Liu K, Guo F, Zhang Y, Zhang G, Jiang C. SARS coronavirus entry into host cells through a novel clathrin- and caveolae-independent endocytic pathway. Cell Res. 2008; 18: 290-301.

128. Simmons G, Reeves JD, Rennekamp AJ, Amberg SM, Piefer AJ, Bates P. Characterization of severe acute respiratory syndromeassociated coronavirus (SARS-CoV) spike glycoprotein-mediated viral entry. Proc Natl Acad Sci USA. 2004; 101: 4240-4245.

129. Matsuyama S, Ujike M, Morikawa S, Tashiro M, Taguchi F. Proteasemediated enhancement of severe acute respiratory syndrome coronavirus infection. Proc Natl Acad Sci USA. 2005; 102: $12543-$ 12547.

130. Belouzard S, Chu VC, Whittaker GR. Activation of the SARS coronavirus spike protein via sequential proteolytic cleavage at two distinct sites. Proc Natl Acad Sci USA. 2009; 106: 5871-5876.

131. Callan RJ, Hartmann FA, West SE, Hinshaw VS. Cleavage of influenza A virus $\mathrm{H} 1$ hemagglutinin by swine respiratory bacterial proteases. J Virol. 1997; 71: 7579-7585.

132. Watanabe R, Matsuyama S, Shirato K, Maejima M, FukushiS, Morikawa $S$, et al. Entry from the cell surface of severe acute respiratory syndrome coronavirus with cleaved $S$ protein as revealed by pseudotype virus bearing cleaved S protein. J Virol. 2008; 82: 11985-11991.

133. Fackler OT, Peterlin BM. Endocytic entry of HIV-1. Curr Biol. 2000; 10: $1005-1008$.

134. Nunes-Correia I, Eulalio A, Nir S, Pedroso de Lima MC. Caveolae as an additional route for influenza virus endocytosis in MDCK cells. Cell Mol Biol Lett. 2004; 9: 47-60.

135. Hagemeijer MC, Rottier PJ, de Haan CA. Biogenesis and dynamics of the coronavirus replicative structures. Viruses. 2012; 4: 3245-3269.

136. Snijder EJ, van der Meer Y, Zevenhoven-Dobbe J, Onderwater JJ, van der Meulen J, Koerten HK, et al. Ultrastructure and origin of membrane vesicles associated with the severe acute respiratory syndrome coronavirus replication complex. J Virol. 2006; 80: 59275940.

137. Imbert I, Snijder EJ, Dimitrova M, Guillemot JC, Lécine P, Canard B. The SARS-coronavirus plnc domain of nsp3 as a replication/ transcription scaffolding protein. Virus Res. 2008; 133: 136-148.

138. Angelini MM, Akhlaghpour M, Neuman BW, Buchmeier MJ. Severe acute respiratory syndrome coronavirus nonstructural proteins 3 , 4, and 6 induce double-membrane vesicles. MBio. 2013; 4: e00524e00513.

139. Knoops K, Kikkert M, van den Worm SHE, Zevenhoven-Dobbe JC, van der Meer Y, Koster AJ, et al. SARS-Coronavirus replication is supported by a reticulovesicular network of modified endoplasmic reticulum. PLoS Biol. 2008; 6: 1957-1974.

140. Ulasli M, Verheije MH, de Haan CA, Reggiori F. Qualitative and quantitative ultrastructural analysis of the membrane rearrangements induced by coronavirus. Cell Microbiol. 2010; 12: 844-861.

141. David-Ferreira JF, Manaker RA. An Electron Microscope Study of the Development of a Mouse Hepatitis Virus in Tissue Culture Cells. J Cell Biol. 1965; 24: 57-78.

142. Deming DJ, Graham RL, Denison MR, Baric RS. Processing of open reading frame la replicase proteins nsp7 to nsp10 in murine hepatitis virus strain A59 replication. J Virol. 2007; 81: 10280-10291.

143. Oostra M, Hagemeijer MC, van Gent M, Bekker CP, te Lintelo, EG, Rottier PJ, de Haan CA. Topology and membrane anchoring of the coronavirus replication complex: not all hydrophobic domains of nsp3 and nsp6 are membrane spanning. J Virol. 2008; 82: 12392-12405.

144. Graham RL, Sims AC, Brockway SM, Baric RS, Denison MR. The nsp2 replicase proteins of murine hepatitis virus and severe acute respiratory syndrome coronavirus are dispensable for viral replication. J Virol. 2005; 79: 13399-13411.

145. Reid CR, Airo AM, Hobman TC. The virus-host interplay: biogenesis of +RNA replication complexes. Viruses. 2015; 7: 4385-4413.

146. Harcourt BH, Jukneliene D, Kanjanahaluethai A, Bechill J, Severson KM, Smith CM, et al. Identification of severe acute respiratory syndrome coronavirus replicase products and characterization of papain-like protease activity. J Virol. 2004; 78: 13600-13612.

147. van der Meer Y, Snijder EJ, Dobbe JC, Schleich S, Denison MR, Spaan WJ, et al. Localization of mouse hepatitis virus nonstructural proteins and RNA synthesis indicates a role for late endosomes in viral replication. J Virol. 1999; 73: 7641-7657.
148. Goldsmith CS, Tatti KM, Ksiazek TG, Rollin PE, Comer JA, Lee WW, et al. Ultrastructural characterization of SARS coronavirus. Emerg Infect Dis. 2004; 10: 320-326.

149. Gosert R, Kanjanahaluethai A, Egger D, Bienz K, Baker SC. RNA Replication of mouse hepatitis virus takes place at double-membrane vesicles. J Virol. 2002; 76: 3697-3708.

150.Spuul P, Balistreri G, Kaariainen L, Ahola T. Phosphatidylinositol 3-kinase-, actin-, and microtubule-dependent transport of Semliki Forest virus replication complexes from the plasma membrane to modified lysosomes. J Virol. 2010; 84: 7543-7557.

151. Hagemeijer MC, Verheije MH, Ulasli M, Shaltiël IA, de Vries LA, Reggiori F, et al. Dynamics of coronavirus replication-transcription complexes. J Virol. 2010; 84: 2134-2149.

152. Reggiori F, Monastyrska I, Verheije MH, Calì T, Ulasli M, Bianchi $\mathrm{S}$, et al. Coronaviruses hijack the LC3-I-positive EDEMosomes, ERderived vesicles exporting short-lived ERAD regulators, for replication. Cell Host Microbe. 2010; 7: 500-508.

153. Kindler E, Jonsdottir HR, Muth D, Hamming OJ, Hartmann $\mathrm{R}$, Rodriguez R, et al. Efficient replication of the novel human betacoronavirus EMC on primary human epithelium highlights its zoonotic potential. MBio. 2013; 4: e00611-12.

154.Al-Tawfiq JA, Momattin H, Dib J, Memish ZA. Ribavirin and interferon therapy in patients infected with the Middle East respiratory syndrome coronavirus: an observational study. Int J Infect Dis. 2014; 20: 42-6.

155.Zumla A, Azhar EI, Arabi Y, Alotaibi B, Rao M, McCloskey B, et al. Host-directed therapies for improving poor treatment outcomes associated with the middle east respiratory syndrome coronavirus infections. Int J Infect Dis. 2015; 40: 71-4.

156. Omrani AS, Saad MM, Baig K, Bahloul A, Abdul-Matin M, Alaidaroos $\mathrm{AY}$, et al. Ribavirin and interferon alfa-2a for severe Middle East respiratory syndrome coronavirus infection: a retrospective cohort study. Lancet Infect Dis. 2014; 14: 1090-5.

157. Shalhoub S, Farahat F, Al-Jiffri A, Simhairi R, Shamma O, Siddiqi $\mathrm{N}$, et al. IFN-alpha2a or IFN-betala in combination with ribavirin to treat Middle East respiratory syndrome coronavirus pneumonia: a retrospective study. J Antimicrob Chemother. 2015; 70: 2129-32.

158. Kawase M, Shirato K, van der Hoek L, Taguchi F, Matsuyama S. Simultaneous treatment of human bronchial epithelial cells with serine and cysteine protease inhibitors prevents severe acute respiratory syndrome coronavirus entry. J Virol. 2012; 86: 6537-45.

159. Simmons G, Zmora P, Gierer S, Heurich A, Pohlmann S. Proteolytic activation of the SARS-coronavirus spike protein: cutting enzymes at the cutting edge of antiviral research. Antiviral Res. 2013; 100: 605-14.

160. Baez-Santos YM, St John SE, Mesecar AD. The SARS-coronavirus papain-like protease: structure, function and inhibition by designed antiviral compounds. Antiviral Res. 2015; 115: 21-38.

161. Lundin A, Dijkman R, Bergstrom T, Kann N, Adamiak B, Hannoun $\mathrm{C}$, et al. Targeting membrane-bound viral RNA synthesis reveals potent inhibition of diverse coronaviruses including the Middle East respiratory syndrome virus. PLoS Pathog. 2014; 10: e1004166.

162.Zhang H, Wang G, Li J, Nie Y, Shi X, Lian G, et al. Identification of an antigenic determinant on the S2 domain of the severe acute respiratory syndrome coronavirus spike glycoprotein capable of inducing neutralizing antibodies. J Virol. 2004; 78: 6938-6945.

163. Bisht H, Roberts A, Vogel L, Bukreyev A, Collins PL, Murphy BR, et al. Severe acute respiratory syndrome coronavirus spike protein expressed by attenuated vaccinia virus protectively immunizes mice. Proc Natl Acad Sci U S A. 2004; 101: 6641-6646.

164. Volz A, Kupke A, Song F, Jany S, Fux R, Shams-Eldin H, et al. Protective efficacy of recombinant modified vaccinia virus Ankara delivering Middle East respiratory syndrome coronavirus spike glycoprotein. J Virol. 2015; 89: 8651-8656.

165. Xia S, Xu W, Wang Q, et al. Peptide-Based Membrane Fusion Inhibitors Targeting HCoV-229E Spike Protein HR1 and HR2 Domains. Int J Mol Sci. 2018; 19(2): 487.

166. Lim Y, Ng Y, Tam J, Liu D. Human Coronaviruses: A Review of VirusHost Interactions. Diseases. 2016; 4(3): 26.

167. Owczarek K, Szczepanski A, Milewska A, Baster Z, Rajfur Z, et al. Early events during human coronavirus OC43 entry to the cell. Sci Rep. 2018; 8: 7124

168. Hulswit R, Lang Y, Bakkers M, Li W, Li Z, Schouten A, et al. Human coronaviruses OC43 and HKU1 bind to 9-O-acetylated sialic acids via a conserved receptor-binding site in spike protein domain A. PNAS. 2019; 116(7): 2681-2690. 